\title{
Dijital Dönüşümle Radyoda Podcast İçeriklerin Üretilmesi ve İncelenmesi: ‘Ntv Radyo' Örneği
}

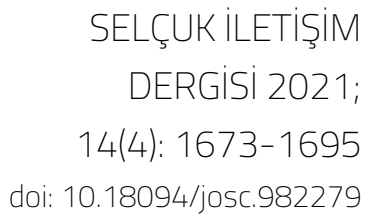

$[\$]$

SYELRIK

ILETISHM

\section{Hülya Semiz Türkoğlu, Mahmut Enes Ağca}

ÖZ

Podcast içerikler dijital dönüşüm sürecinin bir ürünü olarak mobil cihazların yaygınlaşmasıyla birlikte rağbet görmeye başlamıştır. Podcastler, bir içerik türü olmasının yanı sıra aynı zamanda bir iletişim biçimi olarak da öne çıkmaya başlamıştır. Bu çalışmada, NTV Radyo'da yer alan podcast programların yapısal analizi Carvalho, Aguiar ve Marcel'in 2009 yılında ortaya koyduğu sınıflandırma yönteminin uyarlanmasıyla analiz edilmiştir. Bu yöntemle, podcastlerin üretim sıklığı, içeriklerin süreleri, ele alınan konu başlıklarının ve içerik üreticilerinin kimler olduğu gibi sorulara yanıt aranmaktadır. Araştırmada, konu edilen radyo kanalının canlı yayın akışında yer alan podcastler 15 günlük süre içerisinde analiz edilmiştir. Araştırma sonucunda, NTV Radyo bünyesindeki podcast içeriklerin Türkiye'deki diğer geleneksel yayıncıların podcast içeriklerine kıyasla zengin çeşitlilik yapısına ve daha düzenli bir yayın ömrüne sahip olduğu, deneyimli bir yayıncılık anlayışıyla hareket ettiği ve uzun vadeli podcast üretimine yöneldiği ortaya konmuştur. Üretilen podcastlerin, podcast yayıncılıkta dinleyicilerin tercih eğilimleri ile örtüştüğü tespit edilmiştir. Buna karşılık, podcast içerik üretiminde yer alan amatör ruh NTV Radyo tarafından üretilen podcastlerde yer almamaktadır. NTV Radyo podcastlerinin tamamının alanında uzman kişiler ve medya profesyonelleri tarafından hazırlandığı sonucuna ulaşılmıştır. Sonuç olarak, Türkiye'de podcast üretiminde öncü bir konumda olmasına rağmen NTV Radyo'nun dünya genelinde yaygın podcast anlayışı ile örtüşmeyen, podcast yayıncılık konusunda geliştirilmesi gereken yönleri bulunmaktadır.

Anahtar Sözcükler: Dijital Yayıncılık, Podcast, Podcast Çeşitleri, Türkiye'de Podcast, NTV Radyo
HÜLYA SEMIZ TÜRKOĞLU
MAHMUT ENES AĞCA
Dr. Öğr. Üyesi
Doktora Öğrencisi
Istanbul Üniversitesi
Istanbul Üniversitesi
hulyasemiz@istanbul.edu.tr
mahmutenesagca@gmail.com
ORCID ID: 0000-0002-7177-1959
ORCID ID:0000-0003-1944-5635

SELÇUK ILETIŞIM DERGISI 2021; 14(4): 1673-1695

doi: 10.18094/josc.982279

Geliş Tarihi: 12.08.2021 Kabul Tarihi: 03.10.2021 Yayın Tarihi: 25.10.2021 
Producing \& Examining Podcast

Content in Radio with Digital

Transformation: 'Ntv Radyo'

Example
JOURNAL OF SELÇUK

COMMUNICATION 2021;

14(4): 1673-1695

doi: $10.18094 /$ josc. 982279

Hülya Semiz Türkoğlu, Mahmut Enes Ağca

\begin{abstract}
Podcasts has become popular with the spread of mobile devices as a product of the digital transformation process. In addition to being a content type, podcasts are considered as a form of communication. In this study, structural analysis of podcast programs on NTV Radyo was carried out by Carvalho et al. using a method adapted from a 2009 study. With this method, questions such as the frequency of production of podcasts, the duration of content, who are the topics and creators covered are sought. In the study, podcasts in the live broadcast of the radio channel were analyzed over a 15day period. As a result of the research, it was determined that podcast content within NTV Radio has a rich diversity structure compared to other traditional broadcasters in Turkey compared to podcast content, has a regular broadcast range and acts with an experienced publishing approach and has turned to long-term podcast production. Podcasts produced have been found to coincide with the preference trends of listeners in podcast broadcasting. On the other hand, the amateur spirit involved in podcast content production is not included in podcasts produced by NTV Radio. It has been concluded that all NTV Radyo podcasts are prepared by experts and media professionals in their fields. Finally, although NTV Radyo is a pioneer in podcast production in Turkey, there are aspects of podcast publishing that do not coincide with the widespread understanding of podcasts around the world.
\end{abstract}

Keywords: Digital Brodcasting, Podcast, Podcast Types, Podcast in Turkey, NTV Radyo

$\begin{array}{ll}\text { HÜLYA SEMIZ TÜRKOĞLU } & \text { MAHMUT ENES AĞCA } \\ \text { Asst. Prof. } & \text { PhD Student } \\ \text { İstanbul University } & \text { İstanbul University } \\ \text { hulyasemiz@istanbul.edu.tr } & \text { mahmutenesagca@gmail.com } \\ \text { ORCIDID:0000-0002-7177-1959 } & \text { ORCID ID: 0000-0003-1944-5635 }\end{array}$

JOURNAL OF SELÇUK COMMUNICATION 2021; 14(4): 1673-1695

doi: 10.18094/josc.982279 


\section{Gíriş}

Yeni iletişim teknolojilerinin ve internetin gelişimi dijital dönüşümü hızlandırmıştır. Bu doğrultuda, geleneksel yayıncılık anlayışı dijital mecralara odaklanmaya başlamıştır. Geleneksel yayıncılık türlerindeki değişimin yanı sıra, günümüzde özellikle internetin yaygınlaşmasıyla birlikte ücretsiz erişim ya da cüzi ücretli abonelikler sayesinde dijital yayıncılık tercih edilen ve benimsenen bir hale gelmiştir. İnternetin yeniliklere açık yapısı kolektif ve bireysel üretimlere bir pencere açarak yayıncılık anlayışında köklü bir dönüşüme olanak sağlamıştır.

Belirli bir konuda fikir, görüş ve bilgi aktaran ve birçok bölümden oluşan bir (müzik veya konuşma) program olarak podcast kavramına birçok çalışma atıf yapmaktadır. Ayrıca podcastlerin yeni bölümlerine abonelerin otomatik olarak ulaşabildikleri çalışmalarda vurgulanmaktadır. Literatürdeki çalışmalarda ayrıca podcastler; ses dosyalarını, web tabanlı bir altyapıyı ve taşınabilir medya cihazlarını bir araya getirmesi yönüyle birleşik bir medya ürünü olarak kabul edilmektedir (Berry'den aktaran Bonini, 2015, s. 21).

Podcast yayıncılık 2000'li yılların başından itibaren ortaya çıkarak gelişim göstermiş̧ir. Ses dosyalarının kaydedilmesi sonucu üretilen podcastler, geleneksel radyo yayıncılığını da etkilemiştir. Medya profesyonellerinin radyo yayıncılığındaki deneyimlerini ve oluşturdukları programları, bu yeni yayıncılık ve içerik türü olan podcastler ile bütünleştirmeleri önemlidir.

Ayrıca bu etkileşim ve bütünleşme halinin; geleneksel medya araçlarının ayakta kalmasını sağlayacağı düşünülmektedir. Podcast içeriklerin getirdiği yeni reklam pastasından geleneksel radyo yayıncılığı yapan medya kuruluşları ve profesyonelleri de belirli ölçüde faydalanmaktadır. Ürettikleri kaliteli podcast programlarına reklam alan medya kuruluşları ve profesyonelleri gelir elde etmektedir. Ayrıca medya profesyonelleri, mobil teknolojilerin yardımıyla ürettikleri podcast içerikleri (radyo programlarını) depolama ve hedef kitlelerine ulaştırma imkanına da sahiptir.

Bu bağlamda medya profesyonelleri ve bireysel kullanıcıların ses ve video içerikleriyle destekleyerek oluşturdukları podcastler günümüzde giderek yaygınlaşmaktadır. Bu çalışmada yeni bir dijital yayıncılık türü olan podcastler incelemeye tabi tutulmuştur. İnternet, bilgisayar ve mobil cihazların gelişimi ve Covid-19 pandemisi sonrası dijitalleşmenin öneminin artması podcastlerin tüm dünyada yaygınlaşmasına zemin hazırlamıştır. 
Bugün dünya genelinde podcast olarak bildiğimiz içerikler, ilk isimlendirmesiyle "sesliblog" olarak bilinmektedir (Hammersley, 2005). 2004 yılına gelindiğinde Apple şirketinin CEO'su Steve Jobs, şirketin ürünlerinden iPod'u tanıtırken podcastlere yönelik şu öngörüde bulunmuştur: "Podcast, yeni nesil bir radyodur ve kullanıcılar artık 3.000'den fazla ücretsiz podcaste abone olabilir ve her yeni bölümün internet üzerinden bilgisayarlarına ve ipod'larına otomatik olarak indirilmesini sağlayabilir."

Nitekim, Jobs'ın yeni nesil radyo tanımlamasını doğrular nitelikte dünya genelinde radyo yayınlarına olan ilgi azalırken podcast içeriklere olan ilgi ise devamlı artış göstermektedir (National Public Media, 2020). Podcast içeriklerin dinlenme nedenleri üzerine yürütülen bir çalışmada insanların eğlence, zaman geçirme, çeşitli konularda bilgi edinme ve sosyalleşme nedeniyle podcast içeriklere yöneldiği ortaya konmuştur (McClung \& Johnson, 2010, s. 94). Podcastler, içerdiği samimi üslup ve dinleyici ile podcast içeriği üreten arasında bir etkileşimi teşvik etmesi nedeniyle yalnızca bir medya içeriği değil aynı zamanda yeni bir iletişim biçimi olarak görülmektedir (Chan-Olmsted \& Wang, 2020).

Podcast içeriklere olan artan talep incelendiğinde, Avrupa ülkeleri ve ABD'de podcastlerin hızla yaygınlaştığı, yapılan çalışmalarda istatistiki olarak ortaya koyulmuştur. Reuters Enstitü'nün her yıl yayınladığı dijital medya raporları da son yıllardaki podcast dinleme oranlarındaki artışı ülkeler bazında ortaya koymaktadır (Reuters Institute, 2020).

İlgili raporda ülke bazında bir aylık süre içerisinde podcast dinleme oranları belirtilmiştir. İspanya, Avrupa kıtasında yüzde 41 ile nüfusuna oranla podcast içerikleri en çok dinleyen ülke konumundadır. İkinci sırada ise İrlanda, nüfusunun yüzde 40’ının podcast dinlemesiyle öne çıkmaktadır. ABD'de nüfusun yüzde 36'sının podcast içerikleri tükettiği görülmektedir. Illgili çalışmada Türkiye'ye ait podcast dinleme oranına ulaşılamamıştır. Öte yandan dijital müzik servislerinden Spotify verilerine göre, 2020 yılında Türk halkının podcast dinleme oranında yüzde 350 düzeyinde bir artış meydana gelmiştir (Muradoğlu, 2021).

Podcast dinleyicileri üzerine yapılan bir çalışmada, ev ortamında podcast dinleyenlerin daha fazla bilgilendirici içerik ve eğlence unsuru barındıran içeriklere yöneldiği; ev dışında podcast dinleyenlerin ise podcast tüketimini alışkanlık haline getirdiği ve daha uzun süreyle podcast dinledikleri ortaya konmuştur (Chan-Olmsted \& Wang, 2020, s. 17).

Podcast yayınların dinleyicilerine zamana ve mekâna bağlı kalmaksızın dijital ses dosyalarının kayıtlarını mobil cihazlar vasıtasıyla sunmaları teknolojik açıdan önemli bir yeniliktir. Radyo kanalları da 
canlı yayın akışlarındaki programları, arşivleyerek kullanıcılara mobil uygulamalar ve web siteleri üzerinden bu sayede ulaştırmaktadır. Radyonun canlı yayın formatını dönüştüren, üretilen içerikleri kullanıcılara özgü kişiselleştiren ve yayıncılık adına yeni bir alternatif sunan podcast yayıncılı̆̆ı ve içerikleri, bu noktada analiz edilmeye ve incelenmeye değer bir alandır. Bu bağlamda, podcast yayıncılığının gelişimi, geleneksel medyayla olan etkileşimi ve ana akım medya kuruluşlarındaki yarattığı değişim NTV Radyo özelinde yapılacak çalışmayla analiz edilmeye çalışılmıştır.

Araştırmayla birlikte NTV Radyo bünyesindeki podcast programlarının türleri, amaçları, yayınların süreleri, yayın periyotları ve yayınların üreticileri gibi hususlar hakkında bilgi edinmek amaçlanmaktadır. Bu bağlamda araştırmada, geleneksel bir yayıncılık sürdüren NTV Radyo'nun podcast programları nasıl ürettiği ve dinleyicileriyle nasıl buluşturduğu çalışmanın temel araştırma sorusunu oluşturmaktadır.

NTV Radyo bünyesindeki 44 farkıı podcast programı araştırmanın kapsamını oluşturmaktadır. NTV Radyo'da yer alan ilgili podcast programlar 15 günlük bir süre ile sınırlandıılarak incelenmiştir. Bu bağlamda 17.01.2021-31.05.2021 tarihleri arasında NTV Radyo'nun canlı yayın akışı ve podcast yayınların yüklendiği internet sitesi (ntvradyo.com.tr) takip edilmiştir.

Bu araştırmanın yöntemini belirlerken (Carvalho, Aguiar, \& Maciel, 2009) tarafından ortaya konan sınıflandırma modelinin yazarlar tarafından yapılan geliştirilen bir versiyonu kullanılımıştır.

\section{PODCAST KAVRAMI}

Podcast terimi, Apple firmasının ürettiği taşınabilir müzik çalar "iPod" ile İngilizcede "yayın" anlamına gelen "broadcast" sözcüklerinin birleşiminden türetilmiştir. Podcast yayınlar genellikle ses dosyalarından oluşmaktır ve podcast yayınlara birçok farklı yoldan ulaşmak mümkündür. Podcast yayınlar, bir bilgisayara veya mobil cihaza indirilebilme özelliğine sahiptir. Ayrıca podcast yayınların yeni bölümlerine de kullanıcılar, bir uygulama aracılığıyla abone olduğu takdirde, otomatik indirme özelliğinden faydalanarak rahatlıkla erişebilmektedir (Giordano, 2017, s. 430).

Podcast kavramının Türkçe karşılığını sunmaya yönelik çeşitli çalışmalar olsa da (Berk, 2019: 4748) yapılan çalışmaların toplum genelinde bir karşılık bulduğu söylenemez. Dünya genelinde olduğu gibi Türk toplumunda da podcast kelimesi bilinirlik kazanmıştır. Hem bir içerik türü olarak hem de yayınlanma 
ve dağıtılma şekline verilen isim olarak podcast kabul görmektedir. Ayrıca, podcast içerikleri üreten kişiler için de podcaster kavramının kullanıldığı çalışmalarda görülmüştür (Kutlu, 2020, s. 215).

Medya tüketicilerinin içerik üretmesine olanak tanıyan sosyal ağlar ve yeni medya ortamları podcast içeriklerin üretildiği ve erişilebildiği platformlardır. Podcast yayıncılıkta, ses ve video içerikleri, uygulamalar ve mobil cihazlar vasıtasıyla kaydedilerek kullanıcıların hizmetine sunulmaktadır. Podcastlerin kullanıcılarına sunduğu belli başlı avantajları Geoghegan ve Klass (2007) ise, şu şekilde Sıralamıştır:

- Otomatik erişim: Podcastler abonelik sistemiyle otomatik olarak bilgisayarlara indirilebilir. Kullanıcılar takip edilen showlara arama yapılmaksızın erişebilir.

- Kolay kontrol: Podcastler kullanıcılara, içerik üzerinde seçme ve dinleme kontrolü sağlar.

- Taşınabilir olma: Web'den indirilin kalıcı ses ve video dosyaları, mobil telefonlar aracııı̆ıyla hemen her yerde dinleme/izleme firsatını kullanıcılara sunar.

- Her zaman elde edilebilme: Podcastler istenilen her zamanda sabit diskten ya da taşınabilir medya aygıtından elde edilebilir. Kullanıcılar takip ettikleri favori showları böylelikle kaçırmak gibi bir endişeye kapılmazlar (aktaran Akar, 2021, s. 147-148).

Bir konu hakkında bilgilendirici içerik sunma özelliği ile öne çıkan podcast içeriklerin avantajlarına rağmen birtakım dezavantajları da bulunmaktadır. Bruno (2007), eğitim alanında kullanılan podcast içerik ve yayıncılığının yarattığı dezavantajları şu şekilde sıralamıştır:

- Kullanılan akademik içerik eksikliği ve ticari kaynaklardan lisans anlaşmaları zorlukları,

- Teknik sınırlamalar ve eğitim kaynaklarının eksikliği,

- Podcasting işlevselliğinin, fakülteler ve öğrenciler tarafından tam olarak bilinmemesi, bu konudaki bilinç ve bilgi eksikliği olarak sıralanabilir.

- Mevcut teknoloji altyapısıyla bütünleşme sıkıntıları (aktaran Gülseçen vd., 2010, s. 789).

\section{Podcast İçeriklerin Radyodan Ayrılan Yönleri}

Geleneksel radyo yayıncılığının ilk örnekleri telsiz ve telgraftaki teknik gelişmelerin etkisiyle 1920'li yıllarda verilmiştir. İnsan sesinin aktarıldığı ilk radyo yayını 1921'de askeri bir radyo istasyonunda gerçekleştirilmiştir. 1922 yılında Fransa ve İngiltere başta olmak üzere Sovyetler Birliği bu iletişim aracını kullanmaya başlamıştır. 1923 yılına gelindiğinde ABD'de yaklaşık 200 radyo istasyonunun yayın yapmaya başladığı çalışmalarda aktarılmıştır. 1927 yılına kadar olan süreçte Avrupa kıtasında yaygınlaşan radyo yayıncılığı, Güney Amerika ülkesi olan Arjantin'de de hemen hemen dünyanın birçok ülkesinde olduğu gibi benimsenmeye başlamıştır (Aziz'den aktaran Birsen, 2021, s. 24-25). 
Radyo 1920'li yılların başından itibaren 1950'li yıllara kadar olan süreçte ülkelerin siyasi ve toplumsal yaşamında etkin olan bir kitle iletişim aracı olmuştur. Radyo yayınlarının bu dönemde propaganda gücü olarak devletler tarafından kullanıldığı görülmüştür. Radyo istasyonları, 1990'ı yıllardan itibaren internet yoluyla çevrim içi ortamlarda da yayın yapmaya başlamıştır ve dijitalleşmenin ilk adımlarını atmışlardır.

Çevrim içi radyo yayınları internetin yardımıyla, geleneksel radyo yayınları için yeni bir içerik aktarım ortamı sağlamıştır. Çevrimiçi radyolar, geleneksel radyoların uzantıları olarak görülmüştür. Radyo istasyonları için çevrim içi yayınların avantajlarını uluslararası çalışmalardan derleyerek listeleyen Doç. Dr. Sedat Özel (2014), Yeni Medya Çağında Radyoların Dönüşümü adlı makalesinde bu avantajları şu şekilde ifade etmiştir:

- Geleneksel radyo yayıncılığı için hem teknik hem de yasal düzenlemeler anlamında çizilmiş olan yayın sınırlarının aşılması, yayınların daha fazla dinleyiciye ulaştırılmasının önünün açıması,

- Geleneksel radyo yayın alıcıları dışında bilgisayar, tabletler, akıllı telefonlar gibi farkı platformlardan dinleyiciye ulaşılabilmesi,

- Destekleyici ve tamamlayııı bir unsur olarak görsel malzemelerin kullanılabilmesi,

- Dinlevici ile doğrudan ve daha etkili iletişim,

- Dinler kitle profilinin daha net belirlenebilmesi,

- Geleneksel yayınların eş zamanlı olarak aktarılmasının yanında dinleyiciye yayın içeriği arşivinin sunulabilmesi,

- Dinleyici ihtiyaçlarına göre içeriğin özelleştirilebilmesi,

- Radyolar için güçlü ve etkili tanıtım kitlerinin oluşturulabilmesi,

- Kampanya ve reklam pazarlaması için yeni olanaklar sunması (s. 179-180).

Çalışmanın konusu olan podcastleri, internette yayın yapan çevrim içi radyolar ile geleneksel radyo yayınları arasında bir yere konumlayan çalışmalara literatürün oluşmaya başladığı ilk yıllarda rastlamak mümkündür. Podcastlerin geleneksel ve dijital radyolar arasında bir köprü vazifesi gördüğünü belirten yaklaşımların yanı sıra podcastlerin geleneksel radyo yayıncılığının sonunu getirebileceğine yönelik yaklaşımlar da mevcuttur (Berry, 2006; Menduni, 2007).

Yakın dönemde yapılan podcast çalışmalarında ise, podcastler yeni bir dijital sözlü kültür alanı olarak tanımlanmaktadır. Podcastler bu çalışmalarda, düşünce, ses ve metin yazarlığının bir araya geldiği hibrit bir alan olarak tarif edilmektedir. İnternet kullanıcılarının yoğun bir şekilde maruz kaldığı viral reklamlardan podcastlerin uzak olması benimsenmesini kolaylaştıran bir etmen olarak görülmektedir. 
Ayrıca podcastlerin dinleyici ve içerik üreticisi arasında ilgi alanlarına özel tecrübelerin paylaşılması dolayısıyla derin bir bağ kurduğuna dikkat çekilmektedir (Linares, Fox, \& Berry, 2018, s. 4)

Podcast dinleyicisinin radyo dinleyicisinden daha aktif bir konumda yer aldığı çalışmalarda vurgulanmaktadır. Podcast dinleyicisinin radyo dinleyicisine kıyasla ilgi duyduğu içerikleri daha dikkati bir şekilde dinlediği belirtilmiştir. Yine çalışmalarda dikkat çekilen bir diğer husus ise, podcast içeriklerin anlatım tekniğinin radyodan farklılaşmasıdır. Yapılan çalışmalarda podcast içeriklerde sürükleyici bir anlatım tekniğinin kullanıldığı ifade edilmiştir. Içerik üreticisinin kendini hikâye anlatıcı rolüyle kurguladığı yayınlarda anlatılan hikayelerde karakterler ve sahne kurguları üretilmektedir (Newman \& Gallo, 2019, s. 9)

Podcast içeriklerin editoryal bir süzgeçten geçmeyerek üretildiği bireysel girişimler de podcast ekosistemi içerisinde mevcuttur. Bu bağlamda özgün bir üretim ortamının benimsendiği podcastler radyolardan birçok yönüyle ayrılmaktadır. Dijital teknolojilerin kullanımıyla bireysel içerik üreticileri ilgi alanları özelinde çok daha zengin bir içeriği üretme imkanına podcastler yoluyla sahip olmaktadır. Kısaca podcastler, özgün ve bağımsız (denetimden uzak) bir içerik üretimini destekleyen yapılarıyla radyolardan farklılaşmaktadır.

\section{ARAŞTIRMA}

$\mathrm{Bu}$ araştırma makalesinde podcast içeriklerin üretildiği NTV Radyo örneği incelenmiştir. Bu bağlamda örnek olay incelemesi öncesinde araştırmanın amacına, kapsamına ve yöntemine dair ayrıntıı bilgi verilmiştir. Araştırmada örneklem olarak NTV Radyo'nun seçilmesindeki en önemli husus, NTV Radyo'nun Türkiye'de yayın akışında podcast içeriklerine yer veren nadir yayıncıların başında gelmesidir (Tufan, 2020, s. 78).

\section{Araştırmanın Amacı}

Araştırmada NTV Radyo'da yer alan podcast programların yapısal analizi gerçekleştirilmiştir. Podcast kavramı ve yayıncılığına dair literatüre katkı sunacak örnek bir çalışmanın oluşturulması yapılacak araştırmayla hedeflenmektedir.

Araştırmayla podcast programlarının adları, konu başıkları, ilk ve son yayınlandıkları tarih, yayın periyotları, yayınların süresi ve yayınların üreticileri gibi hususlar hakkında bilgi edinmek 
amaçlanmaktadır. Bu bağlamda araştırmada, geleneksel bir yayın organı olan radyonun dinleyicilerine, yeni bir yayıncılık türü olan podcast programları nasıl sunduğuna odaklanılmak istenmektedir. Çalışmada tematik bir haber kanalı olan NTV televizyon kanalının radyo yayınlarıyla dinleyicilerine ne tür farklı podcast programları hazırladığı ve hangi konuları işlediği analiz edilmiştir.

Araştırmanın yöntem kısmında bahsedilecek şablon ışığında; podcast yayınların ne sıklıkla yayınlandığı, podcastlerin süreleri, podcast içeriklerinin konu başıklarının ne olduğu ve içerik üreticilerinin kimler olduğu gibi sorulara yanıt aranmaktadır. Araştırmada, konu edilen radyo kanalının canlı yayın akışında yer alan podcastlerin 15 günlük süre içerisinde takip edilerek yukarıdaki başlıklar özelinde incelenmesi amaçlanmaktadır.

\section{Araştırmanın Kapsamı}

Araştırma kapsamında NTV Radyo bünyesinde yer alan podcast programları ele alınmaktadır. NTV Radyo bünyesinde oluşturulan podcast programlarına https://www.ntvradyo.com.tr/Podcast adlı web sitesi üzerinden ulaşılmıştır. Kurumun web sitesine bakıldığında NTV Radyo'nun geçmiş ve güncel yayın akışında yer alan 44 farklı podcast programının var olduğu bilgisi edinilmiştir. Podcast programların eski bölümlerine ve canlı yayınlarına radyonun web sitesi üzerinden erişim mümkündür.

Araştırmanın evrenini, Türkiye'de yayınlanan farklı içerikteki podcast programları oluşturmaktadır. Araştırmanın örneklemini ise, Türkiye'de kurumsal bir yayıncılık yapan profesyonel bir medya şirketinin radyo kanalında yayınlanan podcast programları oluşturmaktadır. Geleneksel radyo yayıncılığını, ürettiği içerikler ve oluşturduğu programlarıyla, yeni nesil podcast yayıncılığı ile bütünleştiren NTV Radyo, çalışma kapsamında bu bağlamda seçilmiştir.

Literatür çalışmalarında podcast programların birçok dijital yayıncılık platformunun altyapısını kullanarak dinleyicilere hizmet verdiği görülmüştür. NTV Radyo'da yer alan podcast yayınların ise, kurumsal web sitesinde Soundcloud adlı dijital yayıncılık platformu aracılığıyla dinleyicilere ulaştırıldığı görülmüştür. Kurumsal web sitesinde canlı radyo dinleyerek podcast yayınlara ulaşmak mümkün iken, yayını kaçıranlar için Soundcloud aracılığıyla yayının ardından web sitesine içeriklerin arşivlenerek depolanması söz konusudur. Podcastlere ilişkin dinlenme sayılarına da yine site üzerinden ulaşmak mümkündür. 
Ayrıca NTV Radyo'nun podcast yayınlarına App Store ve Play Store mağazaları üzerinden indirilen NTV Radyo mobil uygulaması aracılığıyla erişilebilir. Google podcasts uygulaması, Apple Podcasts uygulaması, Spotify ve Soundcloud gibi farklı platformlar da ilgili podcastlerin yayınlandığı farklı dijital mecralar olarak göze çarpmaktadır. Ayrıca yine site üzerinden podcast yayınları sosyal ağlar vasıtasıyla farklı kullanıcılar ile paylaşmak da mümkündür. Bu bağlamda podcast programların paylaşımı; Facebook, Twitter, Tumblr, Google+, Pinterest ve E-mail gibi sosyal ağlar ve mecralar yoluyla gerçekleşebilmektedir.

NTV Radyo bünyesindeki 44 farklı podcast programı araştırmanın kapsamını oluşturmaktadır. Tematik bir haber kanalı olan NTV Radyo'da ilgili podcast programların halen yayınlanır olup olmadığının incelenmesi açısından araştırma süresi 15 günlük bir süre ile sınırlandırılmıştır. 17.01.2021-31.05.2021 tarihleri arasında NTV Radyo'nun canlı yayın akışı takip edilecektir. Arşivde yer alan 44 podcast program bilgisinin 15 günlük süre içerisinde canlı yayın akışında yer edinip edinmeyeceği araştırmanın önemli sorularından birini oluşturmaktadır.

\section{Araștırmanın Yöntemi}

Bu araştırmanın yöntemi (Carvalho, Aguiar, \& Maciel, 2009) tarafından ortaya konan Podcast sınıflandırma sistemi kullanılarak, bu sisteme birtakım geliştirmeler yapılarak uyarlanmıştır.

Bu bağlamda geliştirilen yöntemin güncel olması ve araştırmaya uyarlanabilirliği hususları dikkate alınarak podcast programları incelemek için ilgili yöntem tercih edilmiştir. Bu bağlamda, 44 farklı podcast programı, 15 günlük süre içerisinde site üzerinden dinlenerek sınıflandırmaya uygun bir biçimde analiz edilmeye çalışılmıştır.

Aşağıda yer alan sınıflandırma yöntemi (Carvalho, Aguiar, \& Maciel, 2009) çalışması temel alınarak oluşturulmuştur:

\section{Içerik Türü (Type)}

- Bilgilendirici: (Podcastin konusunu oluşturan kavramların anlatılması, podcast konusu hakkında analiz yapılması, ilgili konudaki kuramsal çalışmalar ve en son yapılan çalışmalar hakkında dinleyicinin aydınlatılması) 
- Değerlendirme / Yorum: Podcast konusu hakkında eleştirel bir tutum ile dinleyiciye podcast konusu hakkında, podcast üreticisinin görüşlerinin, değerlendirmelerinin paylaşması.

- Rehber / Yönerge: Podcast konusu hakkında dinleyenlerin de uygulayabileceği üzere bilgilendirilmesi, tarif içerikleri, nasıl yapııır? sorusuna cevap verilmesi)

- Yönlendirici: Dinleyenlerin iç dünyalarına hitap eden, belirli hedeflere yönelmiş insanları o yönde daha fazla gayret etmeye teşvik eden, sağlıklı yaşamı özendiren, kişisel gelişim temalı içerikler ile insanları motive etmek amaçlanmaktadır.

\section{Medyanın Türü (Medim)}

- Ses Tabanlı içerik: Salt ses dosyasından oluşan Podcastler.

- Video Tabanlı içerik: Video içeriklerin de olduğu hem ses hem de video tabanlı podcastlerdir.

\section{Podcast Süresi (Length)}

- Kısa (1-5 dakika süreli içerikler)

- Orta (6-15 dakika süreli içerikler)

- Uzun (15 dakikadan daha uzun süreli içerikler)

\section{Podcast Yayıncılığı (Author)}

a. Bireysel

b. Çoklu

c. Topluluk

\section{Yayın Stili (Style)}

a. Kurumsal: Kurum kimliğinin ağırlıkta olduğu, podcast yayıncısından çok podcastin bünyesinde üretildiği kurumun kimliğinin ön planda olduğu içeriklerdir.

b. Bireysel: Podcast yayıncısının biçem bakımından daha özgür biçimde olduğu, doğaçlama yayın yapabildiği, kendi deneyimlerini ve görüşlerini rahatlıkla program içerisinde belirtebildiği türdür. 


\section{Amaç (Purpose)}

Bir konuyla ilgili olarak bilgilendirmek, haberdar etmek, bir konuyu/olayı analiz etmek, fikir ve bilgi paylaşımında bulunmak, harekete geçirmek, motive etmek, yayınlar aracılı̆ııla yansıtıcı öğrenme vb.

\section{Bulgular}

Podcast yayıncılığında Türkiye'de NTV farkıı alanlarda yayınlar yapmaktadır. Yayınlarda müzik ve edebiyattan gastronomiye, spordan haberciliğe kadar birçok alanda podcast bulunmaktadır. Bu podcast yayınlar genellikle izleyicilere kurumun internet sitesi üzerinden ses dosyası şeklinde ulaştırılmaktadır.

NTV kurumunun ürettiği podcast programlarının özünü hem televizyon kanalında üretilen içerikler hem de radyoda üretilen içerikler oluşturmaktadır. Örnek olarak Mete Çubukçu'nun sunduğu Kayıttayız podcast programında dünyada ve Türkiye'de yaşanan gelişmeler, belli temalar üzerine araştırma yapılarak konuklar eşliğinde değerlendirilmektedir. Bir başka örnek ise, Ahmet Yeşiltepe'nin sunduğu Babil Kulesi adlı programdır. NTV Radyo'nun en sevilen belgesel serilerinden birisi olan Babil Kulesi adlı program; insanlık tarihinin sıra dışı öykülerini, farklı coğrafyaların az bilinen geçmişini ve günümüz dünyasının ilham kaynağı olan olaylarını ve kişilerini, renkli alıntılar yaparak dinleyicilerle paylaşmaktadır.

NTV Radyo bünyesinde geçmişten günümüze toplamda 45 podcast içeriğin üretildiği çalışma kapsamında gözlemlenmiştir. 29 adet podcast içeriği NTV Radyo özelinde günümüzde halen aktif olarak hazırlanmaktadır. 16 adet podcast programının ise, geçmişte üretilen arşiv bölümlerine kurumun internet sitesi üzerinden ulaşmak mümkündür. NTV Radyo Soundcloud altyapısını kullanarak radyo programlarının dijital arşivini internet sitesi üzerinden dinleyicilerle buluşturmaktadır.

Bu bağlamda güncel olarak yayınlanan 29 adet podcast içeriği çalışma kapsamında incelenmiştir. Podcastler incelenirken çalışmanın yöntemini oluşturan şablonun dışında ilgili yayınlar bazı kriterlere göre sınıflandırılmıştır. Aşağıdaki tabloda podcast içeriklerin adlarına, yayın sayılarına, yayın periyodlarına ve yayınları hazırlayan kişilerin adlarına yer verilmiştir. 
Tablo 1 Incelenen Podcast Yayınların Adları, Sayıları, Yayın Periyodları ve Podcastleri Hazırlayanların Adları.

\begin{tabular}{|c|c|c|c|}
\hline PODCAST ADI & $\begin{array}{l}\text { YAYIN } \\
\text { SAYISI }\end{array}$ & $\begin{array}{c}\text { YAYIN } \\
\text { PERIYODU }\end{array}$ & HAZIRLAYAN \\
\hline Acı, Tatlı, Mayhoş & 84 & Günlük & Aylin Öney Tan \\
\hline Babil Kulesi & 64 & Haftalık & Ahmet Yeşiltepe \\
\hline Beşerî Münasebetler & 56 & Haftalık & Nezih Orhon \\
\hline Bir Bisiklet Hikayesi & 109 & Haftalık & Günnur Öztürk Yener \\
\hline Can Birsay'la Tekno-N & 420 & Günlük & Can Birsay \\
\hline Cazın Büyüsü & 329 & Haftalık & Hakan Rauf Tüfekçi \\
\hline Caz Tutkusu & 335 & Haftalık & Hülya Cantuğ \\
\hline Caz ve Ötesi & 303 & Haftalık & Sevin Okyay \\
\hline Cinayet Masası & 314 & Haftalık & Sevin Okyay \\
\hline Dinle-Yoga & 29 & İki Haftada Bir & Şengül Dağdeviren \\
\hline Doğa Konuşmaları & 63 & Haftalık & Aynur Altunkaş \\
\hline Doğa Takvimi & 163 & Günlük & Ayşegül Akın Asal \\
\hline Doktor Bana Doğruyu Söyle & 243 & Haftalık & Aykut Altunkaş \\
\hline Dünya Hali & 36 & Haftalık & Derya Acemoğlu \\
\hline Engelsiz & 273 & Haftalık & Ayhan Aktaş \\
\hline Evdeki Hesap & 683 & Günlük & Murat Ferman \\
\hline Eve Dönerken & 1841 & Günlük & Günnur Öztürk Yener \\
\hline İşe Giderken & 2119 & Günlük & Günnur Öztürk Yener \\
\hline İşten Güçten & 1647 & Günlük & Cem Kılıç \\
\hline Kayıttayız & 280 & Haftalık & Mete Çubukçu \\
\hline Köşedeki Kitapçı & 1445 & Günlük & Adnan Bostancıoğlu \\
\hline Kuş Bakışı & 15 & Aylık & Arzu Gürsoy Ergen \\
\hline Masal Bu Ya! & 183 & Haftalık & Judith Liberman \\
\hline Müzik Defteri & 57 & Haftalık & Suat Kavukluoğlu \\
\hline Pötikare & 23 & Haftalık & Nacide Berber \\
\hline Spor Merkezi & 191 & Günlük & Şansın Tokyay, Nebil Evren, vd. \\
\hline Şarkılar ve Hikayeleri & 125 & Haftalık & Can Doğan \\
\hline Şehir Kuşçusu & 26 & İki Haftada Bir & Kerem Ali Boyla \\
\hline 5'te Beş & 50 & Haftalık & Deniz Kilislioğlu \\
\hline
\end{tabular}

Yukarıdaki tabloda yer alan 29 podcast yayın incelendiğinde her podcast içeriğin farklı sayılarda üretildiği görülmüştür. Günlük olarak üretilen podcastlerin program sayılarının daha fazla olduğu görülmüştür. NTV Radyo bünyesinde program sayıları göz önüne alındığında uzun yıllardır devam eden yayınların varlığı göze çarpmaktadır. 2119 program sayısı ile İşe Giderken adlı program NTV Radyonun bünyesinde yer alan podcastler arasında en çok üretilen yayın olmuştur.

Güncel olarak üretilen bu podcast yayınlar; günlük, haftalık, iki haftalık ve aylık olarak dinleyicilerle buluşturulmaktadır. NTV Radyo podcast içeriklerin üretilmesinde en çok haftalık yayın periyodunu tercih ettiği ve içeriklerini buna göre ürettiği gözlenmiştir. 
Yayınları hazırlayan kişilerin cinsiyetleri dikkate alındığında ise, kadın içerik üreticileri ile erkek içerik üreticilerinin dengeli bir dağılımı söz konusudur (12 KADIN ve 13 ERKEK). Kadın içerik üreticilerinin sayısı 12 olsa da kadınlar NTV Radyo bünyesinde farklı yayınların da üreticisi konumundadır.

Kadın içerik üreticilerinin birden fazla program yaptığı radyo kanalında gözlenirken, herhangi bir erkek içerik üreticisinin birden fazla program yaptığına rastlanmamıştır. Bu bağlamda, gazeteci ve spiker Günnur Öztürk Yener NTV Radyo'da en çok içerik üreten kişidir ve 3 yapımın sorumluluğunu üstlenmiştir. Yazar Sevin Okyay ise, Caz ve Ötesi ve Cinayet Masası adlı iki adet programı yayına hazırlamaktadır. Ayrıca gazeteci ve spiker Aynur Altunkaş da Doğa Konuşmaları ve Doktor Bana Doğruyu Söyle adlı programları sunmaktadır.

Tablo 2 Podcastlerin IIlgili Şablon Işığında Sınıflandırmaları Sonucunda Yayınların Türü, Amaçları, iç̧erik Üreticileri, Uzunlukları ve Stilleri.

\begin{tabular}{|c|c|c|c|c|c|}
\hline PODCAST ADI & TÜRÜ & AMACI & $\begin{array}{c}\text { IÇERIK } \\
\text { ÜRETicisi }\end{array}$ & UZUNLUK & STiLi \\
\hline Acı, Tatlı, Mayhoş & $\begin{array}{l}\text { Rehber/ } \\
\text { Yönergeler }\end{array}$ & Bilgilendirmek & Bireysel & Kısa & Kurumsal \\
\hline Babil Kulesi & Bilgilendirici, & $\begin{array}{l}\text { Bilgilendirmek, } \\
\text { Fikir ve Bilgi Paylaşımında } \\
\text { Bulunmak }\end{array}$ & Bireysel & Uzun & Kurumsal \\
\hline Beşeri Münasebetler & Bilgilendirici & $\begin{array}{l}\text { Fikir ve Bilgi Paylaşımında } \\
\text { Bulunmak, Motive etmek }\end{array}$ & Bireysel & Kisa & Kurumsal \\
\hline Bir Bisiklet Hikayesi & Destekleyici & Motive etmek & Çoklu & Kısa & Kurumsal \\
\hline Can Birsay'la Tekno-N & Bilgilendirici & $\begin{array}{l}\text { Bilgilendirmek, } \\
\text { Haberdar etmek }\end{array}$ & Bireysel & Kisa & Kurumsal \\
\hline Cazın Büyüsü & $\begin{array}{l}\text { Değerlendirme/ } \\
\text { Yorum }\end{array}$ & $\begin{array}{l}\text { Eğlendirmek, } \\
\text { Motive Etmek }\end{array}$ & Bireysel & Orta & Kurumsal \\
\hline Caz Tutkusu & $\begin{array}{l}\text { Değerlendirme/ } \\
\text { Yorum }\end{array}$ & $\begin{array}{l}\text { Eğlendirmek, } \\
\text { Motive Etmek }\end{array}$ & Bireysel & Orta & Kurumsal \\
\hline Caz ve Ötesi & $\begin{array}{l}\text { Değerlendirme } \\
\text { /Yorum }\end{array}$ & $\begin{array}{l}\text { Eğlendirmek, } \\
\text { Motive Etmek }\end{array}$ & Bireysel & Kısa & Kurumsal \\
\hline Cinayet Masası & Bilgilendirici & $\begin{array}{l}\text { Bilgilendirmek, } \\
\text { Fikir ve Bilgi Paylaşımında } \\
\text { Bulunmak }\end{array}$ & Bireysel & Orta & Kurumsal \\
\hline Dinle-Yoga & Yönlendirici & $\begin{array}{l}\text { Eğlendirmek, } \\
\text { Motive etmek }\end{array}$ & Bireysel & Orta & Kurumsal \\
\hline Doğa Konuşmaları & Bilgilendirici & $\begin{array}{l}\text { Fikir ve Bilgi Paylaşımında } \\
\text { Bulunmak }\end{array}$ & Çoklu & Orta & Kurumsal \\
\hline Doğa Takvimi & Bilgilendirici & Bilgilendirmek & Bireysel & Kisa & Kurumsal \\
\hline $\begin{array}{l}\text { Doktor Bana Doğruyu } \\
\text { Söyle }\end{array}$ & Bilgilendirici & $\begin{array}{l}\text { Fikir ve Bilgi Paylaşımında } \\
\text { Bulunmak }\end{array}$ & Çoklu & Orta & Kurumsal \\
\hline Dünya Hali & Bilgilendirici & Haberdar Etmek & Bireysel & Kisa & Kurumsal \\
\hline Engelsiz & Destekleyici & Motive Etmek & Çoklu & Kısa & Kurumsal \\
\hline Evdeki Hesap & Bilgilendirici & Bilgilendirmek & Bireysel & Kısa & Kurumsal \\
\hline
\end{tabular}


Bilgilendirici

Eve Dönerken

Işse Giderken

İşten Güçten

Kayıttayız

Köşedeki Kitapçı

Kuş Bakışı

Masal Bu Ya!

Müzik Defteri

Pötikare

Spor Merkezi

Şarkılar ve Hikayeleri

Şehir Kuşçusu

5'te Beş

Bilgilendirici

Bilgilendirici

/Yorum

Bilgilendirici,

Yönlendirici

Yönlendirici

Yönlendirici

Rehber/

Yönlendirici

Yorum

Yönlendirici

Bilgilendirici
Bilgilendirmek,

Haberdar Etmek,

Fikir ve Bilgi Paylaşımında

Bulunmak,

Motive etmek,

Eğlendirmek

Bilgilendirmek,

Haberdar Etmek,

Fikir ve Bilgi Paylaşımında

Bulunmak,

Motive etmek,

Eğlendirmek

Bilgilendirici Bilgilendirmek

Bilgilendirmek,

Haberdar Etmek

Fikir ve Bilgi Paylaşımında

Bulunmak

Değerlendirme

Bilgilendirici,

Eleştiri/Yorum,

Yönergeler ve

Bilgilendirici

Değerlendirme/

Bilgilendirici ve
Haberdar Etmek

Fikir ve Bilgi Paylaşımında

Bulunmak,

Motive etmek

Bilgilendirmek,

Fikir ve Bilgi Paylaşımında

Bulunmak

Fikir ve Bilgi Paylaşımında

Bulunmak,

Motive etmek

Fikir ve Bilgi Paylaşımında

Bulunmak,

Motive etmek

Haberdar etmek

Eğlendirmek,

Fikir ve Bilgi Paylaşımında

Bulunmak

Fikir ve Bilgi Paylaşımında

Bulunmak,

Motive etmek

Bilgilendirmek
Çoklu

Uzun

Kurumsal

Çoklu Uzun Kurumsal

Bireysel Kısa Kurumsal

Çoklu Kısa Kurumsal

Bireysel Kısa Kurumsal

Bireysel Kısa Kurumsal

Çoklu Kısa Kurumsal

Çoklu Orta Kurumsal

Çoklu Kısa Kurumsal

Çoklu Orta Kurumsal

Bireysel Kısa Kurumsal

Bireysel Kısa Kurumsal

Çoklu Kısa Kurumsal

\section{Podcastlerin Türlerine Göre Sınıflandırılması Sonucu Elde Edilen Bulgular}

NTV Radyo'da yer alan podcast yayınlar "Tür" bakımından incelendiğinde, Bilgilendirici türünde 14 podcast, Eleştiri/Yorum türünde 5 podcast, Yönlendirici türünde 3 podcast ve Rehber / Yönergeler türünde ise 1 podcast olduğu bulgulanmıştır. Bu bağlamda ilgili şablon ışığında yer alan tür sınıflamalarının tamamında içerik üretildiği NTV Radyo özelinde gözlemlenmiştir. 
Ayrıca podcast yayınların 15 günlük süreçte takip edilmesi sonucu bazı yayınların tür olarak iç içe geçen yapıda kurgulandığı görülmüştür. Araştırmanın yöntemini oluşturan şablon ışığında bu tarz yayınlar birden fazla tür adıyla sınıflandırılarak tabloda yerini almıştır. Toplamda 6 adet yayın, birden fazla tür kategorisi içerisine dahil olmuştur. Bu 6 adet programda, Bilgilendirici ve Yönlendirici tür sınıflamasının hâkim yapıda olduğu söylenebilir.

Gündem türünün NTV Radyo özelinde üretilen podcastlerde benimsenmesi, NTV grubunun tematik bir haber yayıncılığı yaptığı göz önüne alındığında hem televizyon hem de radyo kanalındaki yayın içeriklerinin örtüştüğü çalışma sonucunda saptanmıştır. Siyaset, ekonomi, teknoloji ve spor içerikleri haberler yoluyla dinleyiciye ulaştırılmaktadır. Başta müzik olmak üzere kültür sanat odaklı bir yayın teması kanal genelinde mevcuttur. Çevre, doğa ve yaşama dönük podcastlerin üretimi de radyo kanalı içerisinde azımsanmayacak bir paya sahiptir.

\section{Podcastlerin Amaçlarına Göre Sınıflandırılması Sonucu Elde Edilen Bulgular}

NTV Radyo'da yer alan podcast yayınlar "Amaçları" bakımından incelendiğinde, "Fikir ve Bilgi Paylaşımında Bulunmak" amacını taşıyan 17 podcast olduğu saptanmıştır. Ayrıca yayınlanan podcastlerin içeriğine bakıldığında ise, "Bilgilendirmek” amacı en sık görülen ikinci amaç olmuştur.

"Motive Etmek" için yapılan 9 podcastin olduğu gözlenirken radyo bünyesinde "Haberdar Etmek" amacını taşıyan ise 7 podcast bulgulanmıştır. "Eğlendirmek" amacını güden podcastlerin sayısının ise 6 olduğu tespit edilmiştir. Yukarıdaki sayısal veriler çalışmada, bir podcast programının birden fazla amaca hizmet edebilir olduğunu göstermektedir.

Bu bağlamda NTV Radyo bünyesinde yer alan podcastlerin yaygın olarak bir konu veya olay hakkında fikir ve bilgilendirme amacını taşıdığını söylemek mümkündür. İçerik üreticileri podcastlerini yukarıdaki amaçlar doğrultusunda şekillendirerek hazırlamaktadır. Bu kapsamda çalışmayla birlikte, podcast yayınların dinleyicilerin farklı ihtiyaçlarını karşıladığı gözlenmiştir.

\section{Podcastlerin İçerik Üreticilerine Göre Sınıflandırılması Sonucu Elde Edilen}

\section{Bulgular}


NTV Radyo'da yer alan podcast yayınlar "iç̧erik Üreticisi" bakımından incelendiğinde, 17 podcast programın "Bireysel" olarak hazırlandığı görülürken 12 podcast programın ise "Çoklu" olarak yani birden fazla kişi tarafından üretildiği saptanmıştır. Araştırmada, topluluk tarafından üretilen herhangi bir içerik ile karşılaşılmamıştır.

Podcast programlarda içerik üreticileri ağırlık olarak uzman konuklarıyla telefon bağlantısı yapma yoluna gitmiştir. Söyleşi ve röportaj gibi edebi türlerin de yayın akışında tercih edildiği görülmüştür. ìki ya da daha fazla kişi ile yürütülen podcast programlarda gündeme ilişkin haberlerin aktarıldığı bulgulanmıştır.

Yayına bağlanan konukların (gazeteci, meteoroloji mühendisi, akademisyen, vs.) yorum ve analizleriyle gündemdeki gelişmelerin ve olayların analiz edilmeye çalışıldığı çalışmada saptan mıştır.

\section{Podcastlerin Uzunluklarına Göre Sınıflandırılması Sonucu Elde Edilen Bulgular}

NTV Radyo'da yer alan podcast programların süreleri incelendiğinde, 18 adet podcastin "kısa" kategorisindeki uzunluk sınıflamasına dahil olduğu görülmüştür. Ayrıca 8 podcastin "orta" uzunlukta olduğu çalışmada gözlenirken 3 adet podcastin ise, "uzun" kategorisinde yer aldığı kaydedilmiştir.

Podcast programların sürelerine bakıldığına yayınların ağılıklı olarak 30 dakika altında oluşturulduğu görülmüştür. Bu bağlamda yayın sürelerinin dinleyici tercihleri dikkate alınarak oluşturulduğu düşünüldüğünde podcast dinleyicilerinin daha az süreli yayınları benimsediği yönünde bir çıkarım yapmak mümkün olabilir.

Ayrıca podcast yayınların uzunlukları da klasik radyo yayıncılığının (sabit yayın süresi) aksine esnek ve değişkenlik gösteren bir yapıdadır. İncelenen podcast yayınların işlenen konu ve aktarılan bilgi bağlamında gün gün veya haftalık olarak değişiklik gösterdiği çalışmada gözlenmiştir.

\section{Podcastlerin Stillerine Göre Sınıflandırılması Sonucu Elde Edilen Bulgular}

NTV Radyo'da yer alan podcast programların stilleri incelendiğinde, podcastlerin tamamının "Kurumsal" bir medya yapısı altında oluşturulduğu görülmüştür. Türkiye'deki bireysel podcast içerik üretiminin hızla arttığı bir dönemde, sadece kendi bünyesindeki gazeteciler ve konunun uzmanı kişilerle podcast içerikleri oluşturan NTV, dışa kapalı bir podcast yayıncılığı yapmaktadır. Bireysel içerik üretimine 
radyo kanalında yer vermeyen NTV, kurumsal radyo yayıncılı̆ını podcast teknolojisini de kullanarak sürdürmektedir.

\section{SONUÇ}

Yeni iletişim teknolojilerinin hizmete girmesiyle birlikte dijitalleşme geleneksel yayınclık anlayışının benimsendiği medya kuruluşlarında dönüşüme yol açmıştır. Podcast teknolojisinin kullanıcı bazlı mobil ve internet ortamında üretilebilir yapısı da NTV gibi kurumsal yayın yapan medya kuruluşlarının ilgisini çekerek ilgili alana yönelmesine neden olmuştur.

Dünyada ve Türkiye'de 21. yüzyılın getirdiği yeni bir teknoloji olan podcast yayıncılığı, internetin yaygınlaşması ve dijitalleşmenin hızlanmasıyla medya profesyonelleri ve bireysel içerik üreticileri tarafından kullanılır hale gelmiştir. Ucuz veya maliyetsiz yapısıyla bireysel içerik üreticilerinin dikkatini çeken podcast hızla dünya genelinde gençler arasında popüler hale gelmiştir.

Covid 19 salgını döneminde evlere kapanan insanların podcast teknolojisiyle tanışması ve bu teknolojiyi benimsediği çeşitli araştırmaların sonuçlarına yansımaktadır. Dinleyici ve içerik üretici sayısının hızla arttığı günümüzde podcast teknolojisi geleneksel ve kurumsal firmaların radyo içeriklerini dönüştürmelerine ve yayınlarını farklı ortamlardan dolaşıma sokmalarına zemin hazırlamıştır.

Bu bağlamda özel sektöre ait bir radyo kanalının (NTV) ürettiği podcast içerikler, çalışma kapsamında incelemeye tabi tutulmuştur. Bu çalışmada ilgili kurumun radyo program formatında ürettiği içerikleri, podcast programı olarak tanımladığı gözlemlenmiştir.

İncelenen örnek bağlamında Türkiye'de radyo yayıncılığı ve podcast yayıncılığı birbirleriyle iç içe geçmiş durumdadır. Radyonun yayın akışında yer alan ve kurumun internet sitesinde podcast teknolojisi kullanılarak üretilen içeriklerin birbirleriyle kesiştiği ve benzer özellikler gösterdiği NTV Radyo özelinde vurgulanması gereken önemli bir noktadır. Sadece podcast teknolojisine odaklanmayan NTV, radyo ve podcast programları bir arada kullanmaktadır.

Podcast içeriklerin sadece internet ve mobil ortamlar için üretildiği bir yapı, kurumda mevcut değildir. NTV Radyo bünyesinde yayınlanan içeriklerin arşivlenerek dijitale aktarılması söz konusudur. Tematik haber programlarını podcast teknolojisiyle birleştiren NTV, gündeme ilişkin haber kuşaklarının 
yanı sıra kültür sanat odaklı programlar da yayınlamaktadır. Bunu da NTV, Soundcloud altyapısını kullanarak gerçekleştirmektedir.

Çalışmanın kapsamı ve yöntemi doğrultusunda NTV Radyo'da yer alan podcast içeriklere dair şu sonuçlara ulaşılmıştır:

NTV Radyo bünyesinde üretilen podcastler, geleneksel medya kuruluşlarının ürettiği Türkiye'deki diğer podcast örneklerinden ayrılmaktadır. Kaliteli ve deneyimli bir yayıncılık anlayışı NTV Radyo'yu sektörde podcast teknolojisinde ön plana çıkarmaktadır.

Podcastlerde işlenen konu ve temaların podcast yayıncılı̆ı̆n benimsediği ve dinleyicilerin tercih ettiği değerlerle (ilham veren, destekleyici, eğlendirici, vs.) örtüştüğü görülmüştür.

Sohbet havasında kültür-sanat konulu podcast programların varlığı ve NTV Radyo'nun tematik bir haber kanalı hüviyetini terk etmeyerek gündeme ilişkin ürettiği yayınlar, NTV medya grubunu podcast yayıncılığa yaklaştırmaktadır.

Podcastlerin uzunluk ve yayın periyotları göz önünde bulundurulduğunda klasik radyo programlarıyla benzerlikler gösterse de podcast yayın sürelerinin genel eğilime uygun dinleyici sıkmayan ve dikkat dağınıklığı yaratmayan bir yapıda olduğu görülmüştür (kısa ve orta uzunlukta tutulduğu gözlenmiştir).

NTV Radyo'da yer alan podcastlerin içerik üreticileri bakımından farklılık görülmemektedir. Bu farklııı̆ın görülmeme nedeni, NTV Radyo podcastlerinin radyo yayınlarının kesitlerinden oluşturulmasıdır. Podcastlerin bireysel üretimi destekleyen ve amatör çabayla üretilen yapısı NTV özelinde kendine yer bulamamıştır.

Dünyada podcast teknolojisinin radyo yayıncılı̆ından farklı bir formata sahip olduğu ve farklı özellikler taşıdığı yönünde bir eğilim söz konusudur. Türkiye'de geleneksel ve dijital yayıncılık türleri arasında entegrasyonun sağlanması gerekmektedir. Türkiye'de podcast teknolojisinin halen gelişmekte olduğu düşünüldüğünde kat edilmesi gereken önemli bir mesafenin olduğu görülmektedir. Türkiye'de medya kuruluşları tarafından üretilen podcastlerin radyo içeriklerinin aynen yayınlanması biçiminde kendini gösterdiği, büyük medya kuruluşlarının dahi podcast üretimine önem vermediği görülmüştür. 
Türkiye'de üretilen podcast yayınların nitelik ve nicelik açısından yetersiz olduğu görülmüştür ve küresel ölçekte rekabetten uzak bir pozisyonda yer aldığı düşünülmektedir.

İncelenen örnek bağlamında Türkiye'de radyo yayıncılı̆̆ı ve podcast yayıncılığının birbirleriyle iç içe geçmiş durumda olduğu görülmektedir. NTV Radyonun yayın akışında yer alan ve öncelikle radyo ortamında yayınlanan içeriklerin daha sonra aynı formun korunarak podcast olarak yayınlandığı tespit edilmiştir. Dolayısıyla, NTV Radyo tarafından üretilen podcastlerin, yalnızca bu mecra için ve özel olarak üretilmiş birincil kaynak içerik değil, ikinci kaynaklardan üretilen podcast özellikleri taşıdığı görülmektedir.

\section{EXTENDED ABSTRACT}

In the research, structural analysis of podcast programs on NTV Radyo was carried out. It is aimed to create a sample study that will contribute to the literature on podcast concept and publishing. It is aimed to learn about the names of podcast programs, topics, date of first and last published, broadcast periods, duration of broadcasts and producers of broadcasts. In this context, the research is intended to focus on how radio, a traditional broadcaster, offers its listeners podcast programs, a new type of broadcasting. In the study, it was analyzed what kind of different podcast programs NTV television channel, which is a thematic news channel, prepares different podcast programs for its listeners and what subjects it processes.

The universe of the research is the podcast programs with different content published in Turkey. The sample of the research is podcast programs broadcast on the radio channel of a professional media company that is a corporate broadcaster in Turkey. NTV Radyo, which integrates traditional radio broadcasting with its content and programs, has been selected in this context within the scope of the study.

44 different podcast programs within NTV Radyo constitute the scope of the research. The research period is limited to a period of 15 days to examine whether the relevant podcast programs are still broadcast on NTV Radyo, a thematic news channel. Between 17.01.2021-31.05.2021, NTV Radyo's live broadcast will be followed. Whether the 44-podcast program information in the archive will be included in the live stream within a 15-day period is one of the important questions of the research. 
Podcast content on NTV Radio was analyzed by Carvalho et al. using a method adapted from a 2009 study.According to the template mentioned in the method section of the research, answers to questions such as how often podcasts are broadcast, the duration of podcasts, what the topics of podcast content are, and who the creators are are sought. In the research, it is aimed to follow the podcasts in the live broadcast of the radio channel and examine them in the above topics within a 15day period.

The findings of the study are as follows:

Considering the number of programs within NTV Radyo, the existence of long-standing broadcasts stands out. With the number of 2119 programs," İşe Giderken" was the most produced podcast of NTV Radyo. These current podcasts; daily, weekly, two-week, and monthly. It has been observed that NTV Radyo prefers the weekly broadcast period in the production of podcast content and produces its content accordingly.

When the podcasts on NTV Radyo were examined in terms of "Type", it was found that there were 14 podcasts in Informative genre, 5 podcasts in the Feedback/Comment type, 3 podcasts in the Supporting type and 1 podcast in the Guidelines type. In this context, it has been observed in NTV Radyo that content is produced in all type classifications in the light of the relevant template.

When podcast broadcasts on NTV Radyo were examined in terms of their" purposes ", it was determined that there were 17 podcasts aimed at" sharing ideas and information". Also, when looking at the content of published podcasts, the goal of "informing" was the second most common goal.

When podcast broadcasts on NTV Radyo were examined in terms of "content producer ", it was found that 17 podcast programs were prepared as" individual ", while 12 podcast programs were produced as" group", that is, by more than one person.

When the duration of podcast programs on NTV Radyo was examined, it was observed that 18 podcasts in the "Short" category. In addition, 8 podcasts were observed in the "Medium" length study, while 3 podcasts were recorded as being in the "Long" category.

When the styles of podcast programs on NTV Radyo were examined, it was seen that all podcasts were created under an "Enterprise" media structure. At a time when individual podcast content 
production in Turkey is growing rapidly, NTV is an outwardly closed podcast broadcaster, creating podcast content only with journalists and experts. NTV, which does not include individual content production on the radio channel, continues its corporate radio broadcasting using podcast technology.

In the context of the sample examined, radio broadcasting and podcast broadcasting are intertwined in Turkey. It is an important point to be emphasized in the NTV Radyo feature, which is included in the broadcast of the radio and where the content produced using podcast technology on the website of the institution intersects with each other and shows similar characteristics. Ntv does not focus solely on podcast technology, but also uses a combination of radio and podcast programs.

As a result, podcast content on NTV Radyo can be said to:

Podcasts produced within NTV Radyo are separated from other examples of podcasts produced by traditional media organizations in Turkey. A quality and experienced publishing approach puts NTV Radyo at the forefront of podcast technology in the sector.

The topics and themes covered in podcasts have been found to coincide with the values adopted by podcast publishing and preferred by listeners (inspiring, supportive, edificient, etc.).

Although podcasts are similar to classic radio shows when considering length and broadcast periods, podcast broadcast times have been observed to be in a structure that does not bore listeners and does not create distractions in accordance with the general trend (it was observed that it was kept below 30 minutes, which was kept very short and short).

\section{KAYNAKÇA}

Acar, E. (2018). Sosyal medya pazarlaması-Sosyal Web'te pazarlama stratejileri. Ankara: Seçkin Yayıncllık.

Berry, R. (2006). Will the iPod kill the radio star? Profiling podcasting as radio. Convergence, 12(2), 143162. https://doi.org/10.1177/1354856506066522 adresinden alındı

Birsen, Ö. (2021). Yeni sesli kültür: Podcast. Ankara: Töz Yayınları.

Bonini, T. (2015). The 'Second Age' of podcasting: Reframing podcasting as a new digital mass medium. CAC23Quaderns del CAC Journal 41, 23-33.

Carvalho, A. A., Aguiar, C., \& Maciel, R. (2009). A taxonomy of podcasts and its application to higher education. ALT-C 2009 'In dreams begins responsibility', (s. 132-140). Manchester. 
Chan-Olmsted, S., \& Wang, R. (2020). Understanding podcast users: Consumption motives and behaviors. New Media \& Society. https://doi.org/10.1177/1461444820963776 adresinden alındı

Giordano, M. J. (2017). Extensive listening using student-generated podcasts. P. Clements, A. Krause, \& H. Brown (Dü.), Transformation in language education. içinde Tokyo: JALT.

Gülseçen, S., Bayrakdar, B., Cilengir, S., \& Canım, S. (2010). Yeni nesil mobil öğrenme aracı: Podcast. akademik bilişim 10'(s. 787-792). Muğla: Muğla Üniversitesi.

Hammersley, B. (2005, Şubat 12). Audible revolution. Ağustos 10, 2021 tarihinde The Guardian: https://www.theguardian.com/media/2004/feb/12/broadcasting.digitalmedia adresinden alındı

McClung, S., \& Johnson, K. (2010). Examining the motives of podcast users. Journal of radio \& audio media, 17(1), 82-95. https://doi.org/10.1080/19376521003719391 adresinden alındı

Menduni, E. (2007). Four steps in innovative radio broadcasting: From quicktime to podcasting. The radio journal International studies in broadcast and audio media, 5(1), 9-18.

Muradoğlu, C. (2021, Nisan 14). Türkiye'de tekil kullanıcı sayısı geçen seneye göre 3,5 kat artan podcast dünyasına bakış. Haziran 10, 2021 tarihinde Webrazzi:

https://webrazzi.com/2021/04/14/turkiye-de-tekil-kullanici-sayisi-gecen-seneye-gore-3-5kat-artan-podcast-dunyasina-bakis/ adresinden alındı

National Public Media. (2020, Ekim). The spoken word audio reports.

https://www.nationalpublicmedia.com/uploads/2020/10/The_Spoken_Word_Audio_Report _2020_Download.pdf adresinden alındı

Newman, N., \& Gallo, N. (2019). News podcasts and the opportunities for publishers. Reuters Institute.

Özel, S. (2014). Yeni medya çağında radyoların dönüşümü. Akdeniz Üniversitesi Iletişim Fakültesi Dergisi(22), 168-189. https://doi.org/10.31123/akil.441962 adresinden alındı

Reuters Institute. (2020). Reuters institute digital news report 2020. Nisan 18, 2021 tarihinde https://reutersinstitute.politics.ox.ac.uk/sites/default/files/2020-06/DNR_2020_FINAL.pdf adresinden alındı

Tufan, F. (2020). Podcastıng trends of radıo stations in Turkey. A. A. Gül, Y. D. Ertürk, \& P. Elmer (Dü) içinde, Digıtal transformatıon in media \& society (s. 63-81). İstanbul: Istanbul University Press. 